\title{
LA EXPORTACIÓN TABACALERA DE EL CARMEN DE BOLÍVAR EN LOS ALBORES DEL SIGLO XX: GUERRA Y TABACO *
}

\author{
Wilson Blanco Romero ***
}

\section{LAS PREMISAS}

Lo primero que constatamos, al mirar el tránsito del siglo XIX al XX, es la presencia de El Carmen de Bolívar, incluida la antigua provincia de su nombre y algunas áreas aledañas, como un gran emporio de la industria tabacalera —entendida ésta como producción artesanal de tabaco- vale decir con exactitud: producción de tabaco negro en rama. Industria cuya producción respondía a tres ámbitos comerciales distintos: el entonces llamado tabaco de consumo, que era el destinado a satisfacer la demanda dentro de la jurisdicción del departamento de Bolívar; la denominada internación, que comprendía la venta de tabaco en los otros departamentos del país; y por último, la exportación.

Aquí hay que precisar que, si bien el tabaco de consumo y el destinado a la internación alcanzaban significativos volúmenes de venta, el tabaco de El Carmen de Bolívar y su provincia mantuvo durante el período estudiado la vocación esencialmente exportadora que traía desde mediados del siglo XIX. Con una producción orientada de manera primordial hacia el mercado exterior, que alcanzó a generar cuantiosas divisas para la región costeña. Constituyendo ya entrado el siglo XX, como aún hoy día, el único emporio tabacalero exportador que queda en nuestro país. País en el cual, como bien

\footnotetext{
* El presente artículo es resultado del proyecto de investigación titulado El Emporio tabacalero de El Carmen de Bolívar: orígenes y contexto histórico, en que desde el año 1994 hemos venido trabajando para optar el título de Magister en Historia de la Universidad Nacional de Colombia. Proyecto de investigación auspiciado por el Centro de Investigaciones Científicas y Tecnológicas de la Universidad de Cartagena.

** Profesor de la Facultad de Ciencias Humanas de la Universidad de Cartagena.
} 
sabemos, el tabaco se había constituido en cierta forma, hacia fines de la época colonial y posteriormente en la segunda mitad del siglo XIX, como el rey de la economía ${ }^{1}$.

Agreguemos aquí, en relación con la divisas generadas por la exportación tabacalera de la región de El Carmen, que hemos encontrado estadísticas que muestran que en el sólo lustro comprendido entre el año 1918 y 1922 la exportación de tabaco de El Carmen permitió el ingreso de un total de $\$ 2 ' 723,385.1$ oro americano ${ }^{2}$ (en adelante se abrevia como oro a. o sea dólares de U.S.A en monedas de oro), suma bastante considerable para la época teniendo en cuenta el alcance de las finanzas departamentales.

En relación con la especialización preponderantemente exportadora del tabaco de la Provincia de El Carmen, cuyo comercio confluía a su cabecera municipal, encontramos el siguiente testimonio, en el acta de la visita practicada, a mediados de 1918, por el Procurador Fiscal en la Admón. de Hda. de la Provincia: "El Sr. Administrador informó que la mayor parte del tabaco que se produce en el Distrito o que se introduce a él, lo destinan a la exportación, según las fianzas que presenta y el dato que suministran los talonarios de las guías expedidas"3.

Pero, considerando tanto el ámbito local como el comarcal, encontramos que la antigua Provincia de El Carmen de Bolívar y lo que pudiéramos llamar su área aledaña, aunque eran una región tabacalera por excelencia, siendo el tabaco su producción proverbial, el potencial productivo de su economía estaba lejos de ser monoproductor. A ese respecto tenemos, en primer lugar, que aunaba a su condición de región tabacalera la de región ganadera, con unas condiciones naturales ${ }^{4}$ que igual que para el tabaco, le permitieron disponer de un hato considerable y de gran calidad.

\footnotetext{
${ }^{1}$ Ver los dos primeros capítulos de este estudio.

2 Ver A.H.C. (Archivo Histórico de Cartagena) "Ecos" (Ecos de la Montaña, de El Carmen de Bolívar), $\mathrm{N}^{\circ} 164,111-23-1922$ cfr. Tabla 1.4 infra.

3A.H.C. Gta. Dptal. Vll-27-1918.

4Ver A.H.C. "La Patria" № 2.049 Vll-2-1929, donde se reputa a El Carmen como "la primera zona agrícola del departamento", y Publicaciones de la Contraloría
} 
Conviene precisar, además, que el agro montemariano y en particular el carmero estaban lejos de ser sólo tabaco y ganado; por el contrario, además del tabaco y la ganadería contaba con una abundante y variada producción de alimentos básicos, frutos, frutas y productos forestales. Hay que agregar aquí, que también participó la región de El Carmen, en cierta forma, de la fiebre del petróleo. Fiebre ligada a la gran expansión financiera que atrajo la mayor inversión directa de capitales norteamericanos a nuestro país a partir de la segunda década del siglo que acaba de pasar ${ }^{5}$, y que en lo que a El Carmen se refiere aún no se le ha dado el estudio que merece.

Lo otro es que, dentro de la economía carmera el único producto de alto valor comercial y con calidad exportadora no era el tabaco. Lo que hemos establecido para el período aquí estudiado es que, de la comarca carmera salió mucho ganado para los mercados nacionales, y aún para los externos; aparte de la venta y exportación de cueros. También salía panela para abastecer regiones de la $\operatorname{Costa}^{6}$; y se explotaban otros productos forestales y silvestres de gran valor para el comercio exterior que así mismo fueron objeto de exportación como el algodón, la tagua, el caucho, la raicilla (o ipecacuana) ${ }^{7}$, el bálsamo de Tolú, la higuereta ${ }^{8}$, incluso pieles de babilla y de otros diversos animales silvestres. Mención especial merece la producción de café de la Cansona, que no sólo fue objeto de consumo local y comarcal, sino que también fue artículo de exportación durante muchas

de Bolívar. El Carmen B., 1946, pág. 7, donde se resalta la ponderación que en su respectivo momento hicieron el viajero franco-alsaciano Luis Striffler a su llegada a la entonces Provincia de Cartagena en 1841 y el empresario tabacalero francés George Barnier establecido en la localidad en 1927, sobre la "extraordinaria feracidad de sus tierras".

5 RIPPY, Fred J., op. cit. págs. 158 y ss. En este libro como en todos los publicados sobre el tema se omite el caso de la región de El Carmen de Bolívar.

${ }^{6}$ Ver A.H.C. "Ecos " N 16 , VI-14-1914 en donde a propósito encontramos un aviso comercial del siguiente tenor: "Pedro Pérez Zambrano, El Rey del dulce por esta comarca; panelas por mayor y por menor".

${ }^{7}$ A.H.C. "Registro de Bolívar" ํo 2823, V-19-1908. "Informe del Prefecto de la provincia del Carmen" donde se presenta una vivida semblanza del rico y diverso potencial agropecuario y forestal de dicha provincia.

${ }^{8}$ A.H.C. "El Porvenir” № 8630, X-26-1927. 
décadas, aún durante los tiempos posteriores al período que aquí estudiamos ${ }^{9}$.

A ese respecto son muy ilustrativas las palabras contenidas en un informe del Gobernador del Departamento de Bolívar como resultado de un viaje por la comarca carmera en 1912:

Al recorrer el camino de Jesús del Río al Carmen tuve ocasión de ver las grandes dehesas de ganado, las sementeras de tabaco, y fui informado de que en la Cansona se cultiva en grande escala el café, de tal modo que en El Carmen no se consume ya café de Santander, ni de Tolima; pues el que se produce alcanza no solo para el consumo de la ciudad, sino también para los pueblos de los alrededores ${ }^{10}$.

Como muestra del rico y diverso potencial exportador de la antigua Provincia de El Carmen de Bolívar, observemos la siguiente tabla, en donde se registran exportaciones de varios productos de la comarca carmera, incluido el tabaco, entre los años 1918 y 1922 por un valor total de casi 3 millones de pesos oro americano:

9 Ver A.H.C. "Ecos" No 1, Vll1-24-1913, en donde a propósito de la diversidad exportadora de la comarca carmera encontramos el siguiente testimonio en un artículo de "Ecos" sobre "la necesidad de un camino de automóviles que nos facilite la comunicación con el río [el río Magdalena]", dice el redactor entre otras cosas lo siguiente: "Es por esta vía [El Carmen-Zambrano] por donde nuestros productos van a los mercados extranjeros,..." Las cursivas son nuestras.

${ }^{10}$ A.H.C. Gaceta Departamental (en adelante G.D.) N 669 X-28-1912. 
TABLA 1

EXPORTACIONES: DIVERSOS PRODUCTOS DE LA REGIÓN DE EL CARMEN. 1918-1922

\begin{tabular}{|c|c|c|c|}
\hline Año & Artículos & Cantidad & Valor \$ oro A. \\
\hline 1918 & $\begin{array}{l}\text { Tabaco, } \\
\text { Cueros, tagua y otros } \\
\text { artículos }\end{array}$ & $\begin{array}{l}37.384 \text { bultos } \\
\text { s.d }\end{array}$ & $\begin{array}{l}\text { s.d } \\
\$ 2.400 .0\end{array}$ \\
\hline 1919 & $\begin{array}{l}\text { Tabaco } \\
\text { Café } \\
\text { Cueros, tagua y otros } \\
\text { artículos }\end{array}$ & $\begin{array}{l}37.961 \text { bultos } \\
6.622 \text { sacos } \\
\text { s.d }\end{array}$ & $\begin{array}{l}\text { s.d } \\
\text { s.d } \\
\$ 7.613 .0\end{array}$ \\
\hline 1920 & $\begin{array}{l}\text { Tabaco } \\
\text { Café } \\
\text { Algodon } \\
\text { Cueros, tagua y otros } \\
\text { artículos }\end{array}$ & $\begin{array}{l}56.464 \text { bultos } \\
855 \text { sacos } \\
622 \text { pacas grandes } \\
\text { s.d }\end{array}$ & $\begin{array}{l}\text { s.d } \\
\text { s.d } \\
\$ 62.765 .45 \\
\$ 13.044 .0\end{array}$ \\
\hline 1921 & $\begin{array}{l}\text { Tabaco } \\
\text { Café }\end{array}$ & $\begin{array}{l}19.882 \text { bultos } \\
3.569 \text { sacos }\end{array}$ & $\begin{array}{l}\text { s.d } \\
\text { s.d }\end{array}$ \\
\hline 1922 & $\begin{array}{l}\text { Tabaco } \\
\text { Café }\end{array}$ & $\begin{array}{l}7.266 \text { bultos } \\
1.031\end{array}$ & $\begin{array}{l}\text { s.d } \\
\text { s.d }\end{array}$ \\
\hline Gran total & $\$ 2^{\prime} 960.149 .0$ & & \\
\hline
\end{tabular}

Fuente: A.H.C. "Ecos" E.C.B. N-º164111-23-1922, Editorial.

Mirando más atrás encontramos que, desde la mitad de la centuria decimonónica, el Distrito de El Carmen de Bolívar, bajo el impulso del auge tabacalero y exportador, venía experimentando un crecimiento demográfico realmente inusitado y convirtiéndose en un gran núcleo agrocomercial "donde se centraliza el movimiento agrícola y mercantil de un área, cuyo radio es de 25 leguas de extensión" como señalaba Don Valentín Pareja, Gobernador de la Provincia de El Carmen, en un informe oficial ${ }^{11}$ Sobrepasando la tasa de crecimiento y alcanzando a distritos que venían ostentando mayor población como Corozal, que del año 1852 al de 1870 pasó de 6.351 habitantes a tan sólo 6.509, mientras que El Carmen dobla su volumen de población en el mismo lapso al pasar de 3.439 a 6.496. Gran crecimiento demográfico que al darse el cambio del siglo continua siendo

\footnotetext{
${ }^{11}$ Ver A.H.C. Gaceta Oficial del Estado Soberano de Bolívar de 1X-30-1862.
} 
notable, pasando del año 1870 al año 1912 de 6.946 habitantes a 16.332 con un incremento del 135\%, arrojando una tasa de crecimiento anual promedio de $3.2 \%$. Con lo que alcanza también al Distrito de Sincelejo e incluso lo sobrepasa un tanto, ya que para 1912 éste sólo registra 16.021 habitantes $^{12}$. Incluso en el censo de 1918, mientras que la Provincia de El Carmen arroja una población de 47.718 habitantes la de Sincelejo sólo alcanza $46.218^{13}$. Y aún para 1936, encontramos que, mientras el Distrito de Sincelejo ostenta 19.521 habitantes, El Carmen lo sobrepasa con 22.144, y se sitúa también por encima del volumen demográfico de Corozal, que tan sólo alcanzaba los 21.832 habitantes entonces ${ }^{14}$.

En lo que a tabaco se refiere, El Carmen de Bolívar respondió favorablemente a los cambios impuestos por el mercado europeo hacia fines del susodicho siglo; los mismos que, como podemos recordar, llevaron al hundimiento definitivo a los centros exportadores del interior del país en el transcurso de su último tercio. Con una ubicación geográfica ventajosa que le permitió costos de transporte hasta los puertos de embarque para el exterior mucho más bajos; con un tabaco apropiado para la fabricación de cigarros baratos, en auge entonces en Europa. Es así como al iniciarse el siglo XX, tras soportar en pie las repercusiones de la Guerra de los Mil Días, como lo hemos ilustrado en nuestra tesis de maestría lo que llamamos acá el emporio tabacalero de El Carmen de Bolívar, se consolida plenamente; quedando, de hecho, como el único y gran centro productor de tabaco para la exportación en Colombia. Al respecto J. P. Harrison precisa que: "Entre las 2 guerras mundiales del S. XX, Carmen (sic), continuó siendo el único tabaco colombiano exportado,...”.

En lo referente a la continuidad exportadora del emporio tabacalero de El Carmen de Bolívar tras el fenecimiento del siglo XIX, veamos los

12 DE PIÑERES, Eduardo G. "Censo general de las poblaciones comprendidas en el territorio de la antigua provincia de Cartagena de Indias". Boletín Historial, Cartagena, año IV, marzo y abril de 1919 , N-47 y 48.

${ }^{13}$ Ver id.

${ }^{14}$ ROMERO AGUIRRE, Alfonso. Geografía Económica de Colombia, Tomo V, Bolívar, Contraloría General de la República, Bogotá, 1942, Ver mapa titulado "Departamento de Bolívar sus principales características por municipio", pp. 72 a 73.

15 HARRISON, J.P. Op. cit. p. 231, la cursiva es nuestra. 
siguientes datos globales que trae el historiador costeño Posada Carbó en su obra de reciente publicación sobre la historia económica del Caribe colombiano. Citémoslo en extenso:

Durante la primera mitad del siglo XX el tabaco del Carmen continuó llegando al mercado internacional. Entre 1900 y 1917 las exportaciones promediaron 3'900.000 kilogramos por año. Una demanda considerable desde Europa, especialmente de Alemania y los Países Bajos, había dado un ímpetu a las exportaciones, pero también de Francia, donde el tabaco era el principal producto de importación desde Colombia en 1922... Entre 1931 y 1937 las exportaciones de tabaco promediaron aproximadamente 1'400.000 kilogramos, y en 1938 alcanzaron los 5'017.042 kilogramos. Según Harrison, el desplome del tabaco proveniente de la economía colonialista del archipiélago malayo y de la India en 1946, dio una ventaja excepcional al tabaco de la costa Atlántica. En 1949 se exportaron más de 4'000.000 de kilogramos de tabaco del Carmen ${ }^{16}$.

Volviendo atrás, con base en las anteriores premisas, y unido el hecho de la preeminencia geográfico-política de El Carmen de Bolívar en la subregión de los Monte de María — que hemos mostrado antes - a su condición de verdadero eje de la economía tabacalera y exportadora de una amplia región; podríamos afirmar, entonces, que la apertura del "Quinquenio de Reyes", hacia el año 1905, encuentra a El Carmen de Bolívar convertido en el más importante centro agro-urbano de lo que acá hemos llamado comarca montemariana ${ }^{17}$. Capital de la más populosa y rica de las provincias de dicha comarca y cabecera de circuito notarial, con una posición geográfica bastante ventajosa; y poseedora de extensos terrenos, provistos de un potencial productivo de diversos artículos de gran valor

16 POSADA CARBÓ, Eduardo. Op. cit. p. 93; sin embargo cfr. A.H.C. 'Ecos" de E.C.B. $\mathrm{N}^{5} 68$ IV15-1917, en donde en un reportaje hecho a Diego Maldonado, comerciante y gran exportador de tabaco de la región de E.C.B, se le pregunta qué número de bultos de tabaco considera él que se exporta anualmente "de aquella región" [de El Carmen] y responde textualmente: "No se puede precisar con exactitud, por cuanto las cosechas fluctúan en razón de la bonanza de los años y de los avances que se hagan. En todo caso podría fijarse un promedio de cien mil (100.000) bultos [que a razón de 65 kilogramos por bulto da unas 6.500 toneladas, como se ve un promedio anual mucho mayor (en algo más del 160\%) que el que trae Posada Carbó]".

17 Ver pie de página $\mathrm{N}^{\circ} 3$,supra. 
económico y comercial. Lo que le permite atraer la presencia y el establecimiento de negociantes y empresarios, no sólo vernáculos y de otras regiones y departamentos del país, sino también extranjeros. Todos los cuales acudían con sus capitales e iniciativas a tratar de hacer fortuna, aprovechando las tantas oportunidades de negocios e inversión que la comarca ofrecía.

En esas condiciones, en los albores del siglo XX, los buenos augurios expresados por el General Reyes, en el mensaje inaugural de su gobierno, con las siguientes palabras: "Para nosotros ahora empieza la época de la ascensión en la vía de la prosperidad y el engrandecimiento" "18 adquirían un gran significado para los carmeros ilustrados. En un mundo en que el desarrollo y el progreso material, en términos de lo que los estudiosos ha llamado la modernización capitalista, se traducía en febril ideal ${ }^{19}$.

\section{LA EXPORTACIÓN TABACALERA: GUERRA Y TABACO}

$\mathrm{Al}$ iniciarse el período que estudiamos, la actividad exportadora de tabaco en rama en la región de El Carmen de Bolívar se encontraba en plena expansión. La revisión de la documentación notarial así permite observarlo. Al registrar un número bastante significativo de transacciones financieras hechas con base en negocios de tabaco de exportación. Transacciones financieras efectuadas tanto por negociantes individuales como por casas de comercio de propiedad de compañías o sociedades colectivas de comercio, que eran quienes movían los mayores volúmenes del negocio. Se trata de las entonces llamadas casas compradoras, que como su nombre lo indica se especializaban en la compra de tabaco en rama para ponerlo en condiciones adecuadas y destinarlo, fundamentalmente, a la exportación a los mercados europeos. Entre esas casas compradoras es notoria la presencia y actividad

\footnotetext{
${ }^{18}$ Ver ARISMENDI POSADA, Ignacio. Op. Cit, p. 196. El General Rafael Reyes, como es sabido, gobernó a Colombia en el quinquenio comprendido entre 1904 y 1909.

${ }^{19}$ Ver SOLANO DE LAS AGUAS, Sergio Paolo. "Trabajo y ocio en el Caribe colombiano", en Historia y Cultura. Revista de la facultad de Ciencias Humanas, U. de Cartagena, Cartagena, Diciembre de 1966, N5 4 p. 66 y ss. especialmente.
} 
de negociantes extranjeros, principalmente europeos: alemanes, italianos, franceses; y además sirio-libaneses.

Sobre la ubicación temporal y las motivaciones de la dinámica expansiva de la actividad exportadora de tabaco en El Carmen de Bolívar, el historiador Posada Carbó en el pasaje antes citado ilústralo siguiente: "Entre 1900y 1917 las exportaciones [de "tabaco del Carmen"] promediaron 3'900.000 kilogramos por año [o sea 3.900 toneladas].Una demanda considerable desde Europa, especialmente de Alemania y los Países Bajos, había dado un ímpetu a las exportaciones;...”. Y tres renglones más abajo continúa: "Las exportaciones a Europa cesaron durante la Primera Guerra Mundial y se reanudaron una vez concluido el conflicto, pero nunca con la intensidad del período de la preguerra" ${ }^{20}$. Al respecto de lo mismo, J. P. Harrison (en quien se apoya Posada Carbó) señala lo siguiente: "Los embarques de tabaco Carmen a Alemania continuaron incrementándose gradualmente hasta 1914 cuando la guerra europea temporalmente terminó el comercio, justamente el control británico de los mares causó la abrupta ruptura", y un párrafo más abajo agrega el mismo autor: "Entre las dos guerras mundiales del siglo XX, Carmen (sic) continuó siendo el único tabaco colombiano exportado, pero nunca en cantidades iguales a la era de la Primera Guerra Mundial"21.

De esa "demanda considerable desde Europa", que en consideración de Posada Carbó da ímpetu a las exportaciones de "tabaco Carmen" (como se le conocía en Europa al tabaco de la región de la cual era eje El Carmen) originando un período de expansión durante los primeros lustros del siglo $\mathrm{XX}$, tenemos pleno testimonio tanto en lo que hace a Alemania como a los Países Bajos (Holanda). En relación con Alemania, observamos a través de la documentación notarial la activa presencia en El Carmen de Bolívar y su provincia, además de negociantes y Cías, criollas, de varias compañías alemanas dedicadas a la compra de tabaco para la exportación tales como Flohr Priece \& Co., A. Held de Bremen, O'Berne y Co. ${ }^{22}$ y Gruner \&

20POSADA CARBÓ, Eduardo. El Caribe Colombiano, p. 92.

21Ver HARRISON. The Colombian tobacco... p. 231.

22De esta compañía, que exportaba tabaco a Alemania y estaba gerenciada en El Carmen a comienzos del S. XX por el germano F. Hollmann, sabemos que "estuvo compuesta por el ciudadano francés 
Rieque $^{23}$; y en lo que respecta a Holanda encontramos una nota, publicada en noviembre de 1917 en plena guerra europea, enviada por el cónsul colombiano en ese país, con un requerimiento sobre tabaco, en los siguientes términos: "Hay en Holanda especialmente en Amsterdam... un gran interés por el tabaco del Carmen, muy conocido-apreciado(sic) y solicitado. Casas fuertes importadoras solicitan informes de este Consulado General, muestras, precio y cantidad que podría obtenerse"24.

Esa expansión exportadora del tabaco de El Carmen se refleja directamente en las cifras de exportación de tabaco que da para Colombia José Antonio Ocampo, teniendo en cuenta que desde antes de iniciarse el siglo XX ya la región de El Carmen había quedado prácticamente como el único centro exportador de tabaco en Colombia, como lo sostiene John Parker Harrison en su tesis doctoral. Veamos en la siguiente tabla:

Oswaldo Berne y por el subdito alemán Cari Teodor Prencke, ambos vecinos de Barranquilla"; ver ZAMBRANO PÉREZ, Milton. El desarrollo del empresariado en Barranquilla 1880-1945, Barranquilla, Fondo de Publicaciones de la U. del Atlántico, 1998, pag. 86.

23Ver AH.C prot. E.C.B. Escrituras (esc.) N-10 1V-12-1900;9 11-11-1901; 13 11-12-1901; 21111-101901; 107 V-9-1903; 183 Vll-27-1903y 95 Vl-30-1908. Por ejemplo.

24AH.C. G.D. N²223X1-23-1917. 
TABLA 2

EXPORTACIONES DE TABACO DE COLOMBIA. 1905-1910

\begin{tabular}{lc}
\hline Año & Toneladas \\
\hline 1905 & 2429.1 \\
1906 & 3756.5 \\
1907 & 7475.7 \\
1908 & 3815.4 \\
1909 & 5049.2 \\
1910 & 4419.6 \\
Promedio & 4490.9 \\
\hline
\end{tabular}

Fuente: OC AMPO, José Antonio. Colombia y la economía mundial. 1830-1910, Bogotá, Siglo XXI, 1984, pág. 225.

Examinando la cuestión, notamos en la cita de arriba cómo Posada Carbó extiende la expansión exportadora hasta el año 1917 (esto no obstante que dice que "Las exportaciones a Europa cesaron durante la Primera Guerra Mundial", la cual concluyó a fines de 1918), mientras que Harrison la lleva sólo hasta 1914, año en que se inicia la guerra europea. También observamos que ambos autores, palabras más palabras menos, afirman que las exportaciones de tabaco de El Carmen "cesaron durante la Primera Guerra Mundial"; interrupción de la cual Harrison señala que estuvo ocasionada por el control británico de los mares.

Sobre lo anterior, tenemos que decir que en nuestra investigación hemos encontrado testimonios que indican que durante los años de la guerra europea, las exportaciones de tabaco en rama, si bien mermaron en relación al período anterior, no se interrumpieron, sino que continuaron dándose en volúmenes significativos, como trataremos de demostrar a continuación.

Así, miramos cómo el periódico "Ecos de la Montaña" de El Carmen de Bolívar (en adelante "Ecos") en la edición de Xl-22-1914, meses después de iniciada la guerra europea, hace referencía a un discurso del parlamentario sincelejano José A. Valverde en el Congreso, en el que afirma que El Carmen "exporta anualmente de 60 a 80 mil bultos de tabaco"25 (que calculados a razón de 65 kilogramos por bulto arrojaría un

25A.H.C. “Ecos de la Montaña”'E.C.B. NM7 X1-22-1914. 
promedio de entre 3900 y 5200 toneladas). En informe del Director Subalterno de Estadística sobre la Provincia de El Carmen - especializada en la producción para la exportación - se dice que en 1914 el cultivo de tabaco ascendió "a la cantidad de 4'582.700 el número de matas sembradas; pero con motivo de la guerra europea se ha dejado de la mano y se han dedicado al cultivo del café," 26 .

Por otra parte, en una carta de abril 10 de 1917, publicada en "Ecos", sobre el tema de las repercusiones para la economía colombiana de la entrada de Estados Unidos a la "Guerra Europea” se advierte que: “...serán desastrosas porque la interrupción de los transportes impedirá los intercambios afectando especialmente las industrias del tabaco y en la en ciernes del café!" ${ }^{27}$. Con lo cual se colige que la interrupción de los transportes que paralizó las exportaciones al mercado alemán con motivo de la guerra, debió producirse no en los primeros años de la mencionada guerra, sino a partir de 1917 tras la entrada de Estados Unidos a favor de los aliados que se anunció sólo hasta abril 4 de ese año. Lo otro que no podemos desconocer es que ante el bloqueo inglés, los alemanes continuaron su comercio marítimo a través de los países neutrales ${ }^{28}$.

En un reportaje hecho a Diego Maldonado, comerciante y gran exportador de tabaco de la región de El Carmen, por un diario de Barranquilla y reproducido por "Ecos" a principios de 1917, se le pregunta qué número de bultos de tabaco considera él que se exporta anualmente de aquella región (de El Carmen) y responde textualmente:

No se puede precisar con exactitud, por cuanto las cosechas fluctúan en razón de la bonanza de los años y de los avances que se hagan. En

26A.H.C. G.D. NM525 V111-20-1915.

27 A.H.C. "¿icos” N-68 IV-15-1917 dicha carta que aparece firmada con el seudónimo de "CORRESPONSAL" por el estilo parece ser del notable empresario carmero Don Manuel B. Romero, quien partcipó en el negocio de exportación tabacalera y cafetera, y tenía fincas de café en la zona de "La Cansona" desde donde fue enviada la carta. Las cursivas y el resaltado es nuestro.

28Ver. FERRO, Marc. 'La Gran Guerra (1914-1918)" en: Historia Universal Salvat, Barcelona, 1987, p. 56, donde leemos al respecto lo siguiente: "Para aniquilar al adversario los aliados trataron de arruinar su comercio marítimo, con lo que esperaban destruir las bases de su economía... Los alemanes, sorprendidos por semejantes medidas, no se preocuparon en un primer momento, pues el comercio con los países neutrales les permitía paliar los inconvenientes de la situación". 
todo caso podría fijarse un promedio de cien mil (100.000) bultos [que a razón de 65 kilogramos por bulto da unas 6.500, toneladas, dato al parecer exagerado como promedio anual].

Por ningún lado de dicho reportaje, bastante extenso, se hace la menor referencia a la guerra europea $m$ en particular a interrupción o problema alguno ocasionado por ella a las exportaciones de tabaco a Europa. El tabacalero entrevistado habla, sí, del problema de la notoria disminución sufrida por el tabaco de consumo "en primer término por los impuestos que pesan sobre él en cada Departamento" 29 . Por otro lado, en el acta de la visita practicada por el Procurador Fiscal en la Administración de Hacienda de la Provincia de El Carmen (terminada en VII-11-1918), se encuentra el siguiente dato, muy revelador, sobre la continuidad de las exportaciones durante la época de la guerra: "El Sr. Admor. informó que la mayor parte del tabaco que se produce en el Distrito o que se introduce a él, lo destinan a la exportación, según las fianzas que presenta y el dato que suministran los talonarios de las guías expedidas" ${ }^{\prime 3}$. Además, en un editorial de "Ecos", de marzo de 1922, sobre el agente comercial y tabacalero francés Francisco Degioanni, se calcula la exportación de tabaco "del Carmen (sic)" del año 1918 (el último año de la guerra) en 37.384 bultos, iguales aproximadamente a unas 2.430 toneladas "que reportaron divisas por $\$ 639.266 .4$ oro americano"31.

Como complemento de los datos del editorial sobre el empresario francés, son muy ilustrativos y concluyentes los comentarios hechos en un artículo titulado "El Tabaco del Carmen", que exalta la importancia y vigor de la industria no obstante las dificultades del momento; artículo publicado a principios de septiembre del año 1918 por un hombre tan atento y preocupado por los problemas de El Carmen como Don Abraham Arroyo, director de "Ecos", quien escribe:

Es verdad que este negocio ha sufrido declinaciones sensibles, que no sabemos a qué atribuirlas, si a la baja calidad o al aumento de

\footnotetext{
29A.H.C. "Ecos" 68 1V-15-1917.

${ }^{30}$ A.H.C. G.DN22431 V11-27-1928

31A.H.C. Id. N*111-23-1922.
} 
producción en los mismos mercados consumidores [es significativo que en este pasaje tampoco se mencione la guerra]; sea de lo que ello fuere, El Carmen vale por su tabaco su enseña indiscutible... Un artículo exportable siempre ensancha el comercio..." y dos párrafos más adelante agrega: "Aquí, donde hay tantos compradores como sembradores, nadie desmaya. Unos caen y otros se levantan, sin temor a los obstáculos engendrados por el actual conflicto mundial”. Y en seguida concluye: "Negociantes ha habido, que en la cosecha de ahora, han abierto operaciones, por cerca de cien mil dollars ${ }^{32}$.

Un monto que, calculados a 10 pesos el quintal, promedio que establecimos para el año $1919^{33}$, arroja un volumen de casi 1.000 toneladas, cuantioso para un solo negociante (tengamos en cuenta que Posada Carbó calcula para el período de expansión de 1900 a 1917 un promedio de 3.900 toneladas de tabaco de El Carmen exportado por año). De lo cual es fácil deducir que, en un momento en que la llamada "gran guerra europea" aún no había terminado, $m$ era posible predecir cuándo terminaría, la negociación de tan grandes volúmenes de tabaco por parte de algunos negociantes, indica forzosamente que las condiciones para la exportación de tabaco en ese año no eran nada malas; y que aún menos se podría pensar en que la exportación estuviera paralizada por dicha guerra. Que sólo terminó oficialmente con el armisticio de Rethondes pedido por los alemanes y firmado el 11 de Noviembre de 1918 por los aliados tras la abdicación de Guillermo $\mathbb{I}^{34}$.

Queda claro, pues, ante el ilustrativo testimonio de un contemporáneo como Don Abraham Arroyo, que la ocurrencia de la Primera Guerra Mundial no pasó de significar tan sólo "dificultades u obstáculos" para la industria principal de El Carmen, como él escribe. Dificultades u obstáculos que para nada paralizaron su producción ni hicieron cesar su exportación en grandes cantidades como acabamos de demostrar.

\footnotetext{
${ }^{32}$ A.H.C. Id. N ${ }^{\circ} 103$ IX-13-1818. Las cursivas son nuestras. 33Ver A.H.C prot. E.C.B esc. Nos. 17,18, 132 y 139 de 1919.

34 Ver Diccionario enciclopédico Larousse, Bogotá, Planeta Colombiana Editorial S. A, 1984, vol. IV, p. 1.118, artículo sobre la Primera Guerra Mundial; cfr. Larousse Diccionario Enciclopédico 2000, Santafé de Bogotá, 1999, p. 1.370.
} 
Todo lo anterior indica, de manera palmaria, que no hubo tal cese o ruptura de las exportaciones de tabaco de El Carmen a Europa durante los años de la Primera Guerra Mundial, como lo sostienen Harrison y Posada Carbó; y que dichas exportaciones aunque tuvieron dificultades y diminuyeron de manera significativa en relación con los años inmediatamente anteriores, esa disminución sólo se dio en los dos primeros años de la guerra, porque en los dos últimos - 1917 y 1918 - hubo una notoria recuperación.

El asunto es que las exportaciones de tabaco de El Carmen no dejaron de presentarse en volúmenes y valores bien significativos durante cada uno de los 4 años que duró la guerra, de tal manera que se mantuvieron, aún en los años en que la disminución fue más pronunciada, por encima del $1 \%$ del total de la composición porcentual de las exportaciones colombianas para esos mismos años. De forma indirecta lo demuestran los datos de la siguiente tabla, temiendo en cuenta que como lo sostiene Harrison ${ }^{35}$, el único tabaco colombiano exportado desde fines del siglo XIX era el "tabaco Carmen":

TABLA 3

PORCENTAJES DE TABACO SOBRE EL TOTAL DE LAS EXPORTACIONES COLOMBIANAS. 1912-1922

\begin{tabular}{cc}
\hline Año & Porcentaje \\
\hline 1912 & 1.4 \\
1913 & 2.7 \\
1914 & 1.2 \\
1915 & 1.1 \\
1916 & 1.1 \\
1917 & 1.7 \\
1918 & 2.8 \\
1919 & 3.5 \\
35 VerHARRISON, Jhon'22arker. Op. cit., págs. 229-230. & 0.5 \\
\hline
\end{tabular}


Fueron tan significativos los volúmenes y valores de la exportación del tabaco de El Carmen durante los años de la Gran Guerra Europea que, en una monografía publicada por la Contraloría de Bolívar con el título de $E l$ Carmen B., se dice al respecto, de manera un tanto exagerada, pero aportando una explicación adicional sobre el asunto, lo siguiente: "La exportación tuvo su máximo esplendor durante la guerra del año de 1914 (sic), cuando las necesidades originadas de esa contienda hicieron más imperiosa la salida del artículo a las zonas de abastecimiento de las tuerzas beligerantes" 36 .

Lo que sí parece haber ocurrido es que, por efecto del control británico de los mares, al que hace mención Harrison en el pasaje arriba citado, el destino de las exportaciones durante esos años no fue Alemania, cuya navegación y puertos desde luego estaban afectados por dicho bloqueo marítimo; pero sí Inglaterra y Francia, países aliados en la Triple Entente y enemigos de Alemania, que no tenían tal problema ${ }^{37}$. La cuestión es que el cese de las exportaciones colombianas a Alemania y su continuación a otros países europeos, no afectados por el referido bloqueo, como Inglaterra y Francia principalmente, no cobijó sólo a las exportaciones de tabaco, sino también a las de los demás productos que se venían mandando de antes de la guerra, por lo que podemos ver en la siguiente tabla:

36 Contraloría de Bolívar. (Monografía) El Carmen B. Publicaciones de la Contraloría de Bolívar, 1946, pág. 21.

37 Ver Diccionario Enciclopédico Larousse, Bogotá, Planeta Colombiana Editorial S.A., 1984, p. 1.116, en donde al respecto encontramos lo siguiente en el artículo correspondiente a la Primera Guerra Mundial: "Guerra Naval. Los aliados, superiores gracias a la participación de Gran Bretaña, se adueñaron del mar e impusieron un bloqueo a lo imperios centrales [encabezados por Alemania], a los que pretendían 'asfixiar'....". 
TABLA 4

COMPOSICIÓN PORCENTUAL DE LAS EXPORTACIONES COL. POR PAÍSES DE DESTINO

\begin{tabular}{lccc}
\hline Años & Gran Bretaña & Francia & Alemania \\
\hline 1913 & 16.9 & 2.6 & 9.0 \\
1914 & 17.3 & 1.6 & 6.5 \\
1915 & 12.2 & 7.4 & - \\
1916 & 2.1 & 1.3 & - \\
1917 & 1.5 & 1.7 & - \\
1918 & 0.7 & 2.0 & - \\
1919 & 3.4 & 3.0 & 0.3 \\
\hline
\end{tabular}

Fuente: TOVAR ZAMBRANO, Bernardo. "La economía colombiana (1886-1922)" en: Nueva Historia de Colombia. voi. V. p. 46.

Al respecto de la continuación de los negocios de exportación de tabaco de El Carmen a Inglaterra y Francia como mercados alternos ante el cierre temporal del mercado alemán por efectos derivados de la guerra, es muy sugerente, por una parte, el hecho de que el comerciante, tabacalero y exportador Diego Maldonado, que nombramos atrás, en agosto de 1916 (algo más de dos años después de iniciada la guerra) otorgue poder especial al abogado

Rogelio García A. (vecino de Barranquilla) para que promueva las acciones judiciales necesarias contra los Srs. Scholss Brothers de Londres (Tracey Brothers) para que le rindan cuentas o le paguen lo que ésta arroje a su favor... por haber fallado al cumplimiento en la condición de comisionistas para vender... tabaco $^{38}$.

Como también es sintomático el hecho de que el empresario francés "don Francisco Degioanni G. ...(viniera) al País (sic) en 1918 investido del cargo de Apoderado General de la firma Duhart Freres \& Co. de París, el Habré (sic) y Bordeaux" estableciéndose por varios años en El Carmen de Bolívar,

38A.H.C. Prot E.C.B 153 Vll1-31-1916. La cursiva es nuestra. 
donde se dedicó a la gestión de negocios de tabaco ${ }^{39}$, sin lugar a dudas tabaco de exportación ${ }^{40}$.

En relación con las actividades del gran hombre de negocios que fue Diego Maldonado, al respecto del mismo asunto de los mercados alternos ante el cierre del mercado alemán en la época de la Primera Guerra Mundial, veamos el siguiente dato, realmente concluyeme, que trae un periódico carmero del año 1920 en un artículo dedicado a mostrar su gran trayectoria de negociante emprendedor y exitoso:

...La guerra europea que para muchos fue fuente de desastres, para él fue ventajosa, pues cuando nadie encontraba salida para sus productos, su inventiva le hizo encontrar mercados donde nadie soñó antes que pudiera conseguirse... y un poco más adelante: "Como una muestra de su actividad citaremos el hecho de haber comprado durante el año de 1919 una cantidad no menor de 75.000 pacas de tabaco..."41.

Para mayor ilustración, anotemos que no sólo fue el caso del tabaco de la región de los Montes de María, en Colombia. Con la exportación de la región tabacalera del Cibao en República Dominicana, que igualmente se especializaba en la exportación de tabaco negro en rama y tenía a Alemania como su principal mercado, ocurrió algo similar con motivo de dicha guerra; como lo describe el historiador holandés Michiel Baud en su obra, veamos:

Como consecuencia del estallido de la Primera Guerra Mundial en 1914 y la ocupación norteamericana en el país (República Dominicana) que se inició en 1916, las relaciones comerciales con Alemania se suspendieron y se presentó la necesidad inmediata de encontrar nuevos mercados para el tabaco. El cierre del mercado alemán fue lamentado por unos pocos. Los mercados alternos parecían

39A.H.C. Id. 164111-23-1922. La cursiva es nuestra.

40 A propósito, datos parciales nos han permitido constatar la exportación de 221.8 tons. de tabaco en rama con destino a Francia por el puerto de Cartagena durante los meses de marzo, abril y mayo de 1919, por valor de \$63.646.0. Ver Gacela Comercial de la Cámara de Comercio de Cartagena Nos. 28, 29 y 30 de Vl-30-1919.

41A.H.C. Miscelánea "Centinela” E.C.B. No .7 Xll-18-1920. La cursiva es nuestra. 
ofrecer propuestas promisorias e, inicialmente, el optimismo reinó en el Cibao Todos los gobernadores provinciales del Cibao recibieron una carta del Secretario de Estado de Agricultura en marzo de 1915 en la que decía que Francia estaba interesada en comprar el tabaco dominicano que no se pudiera embarcar hacia Alemania por la guerra. De acuerdo a la carta, el régimen francés estaba preparado para convertirse en un comprador regular de una gran cantidad de tabaco dominicano: "lo que a Francia interesa es establecer un comercio constante entre las dos Repúblicas y sustituir definitivamente a Alemania como cliente y como comprador"... ${ }^{42}$.

Podemos establecer así, entonces, que, durante los años de la Primera Guerra Mundial cesaron o se paralizaron las exportaciones de tabaco "del Carmen", sí pero a Alemania, como al parecer sucedió con los demás productos colombianos que se exportaban a ese país, por el bloqueo marítimo impuesto por Gran Bretaña, al que hace referencia Harrison; sin embargo, continuaron en volúmenes considerables a Inglaterra y Francia, constituidos en mercados alternos. Por otro lado, parece ser que incluso a Holanda (Países Bajos) hubo exportaciones, como lo sugiere de manera evidente el informe del Cónsul General de Colombia en ese país fechado en 1917 y antes citado (ver supra cita $\mathrm{N}^{\circ} 24$ ).

Así que lo antes expuesto nos lleva a concluir que la ocurrencia, entre mediados de 1914 y fines de 1918, de la llamada Gran Guerra Europea, que se conocería posteriormente como Primera Guerra Mundial, no significó para nada el corte o cese del flujo de la exportación del tabaco de El Carmen a Europa, como han creído y sostenido, sin el debido fundamento, respetables autores de nuestros tiempos como Harrison y Posada Carbó y otros del pasado como Alfonso Romero Aguirre, quien refiriéndose a la trayectoria "veintesecular" de la exportación tabacalera de El Carmen escribe: “...al estallar el conflicto en 1914 la industria sufrió un colapso del cual no pudo recuperarse en todos los años de paz que siguieron antes de

42Ver BAUD, Michiel. Los cosecheros de tabaco. La transformación social de la Sociedad Cibaeña, 1870-1930, Santiago de los Caballeros: Pontificia Universidad Católica Madre y Maestra, CEUR, 1996, pág. 128 
que nuevamente estallara la conflagración”,43. Contrario a eso hemos visto cómo esas exportaciones se mantuvieron durante esos años y continuaron con más vigor en los años inmediatos a su terminación, como se puede ver en la tabla de arriba.

${ }^{43}$ ROMERO AGUIRRE, Alfonso. Geografía Económica de Colombia. Tomo V, Bolívar, Contraloría de la República, Ed., El Gráfico, Bogotá, 1942, pag. 351 